\title{
Evaluation of reference genes in mouse preimplantation embryos for gene expression studies using real-time quantitative RT-PCR (RT-qPCR)
}

Jae-Kyo Jeong, Min-Hee Kang, Sangiliyandi Gurunathan, Ssang-Goo Cho, Chankyu Park, Han Geuk Seo and Jin-Hoi Kim ${ }^{*}$

\begin{abstract}
Background: Real-time quantitative reverse-transcriptase polymerase chain reaction (RT-qPCR) is the most sensitive, and valuable technique for rare mRNA detection. However, the expression profiles of reference genes under different experimental conditions, such as different mouse strains, developmental stage, and culture conditions have been poorly studied.

Results: mRNA stability of the $a c t b$, gapdh, sdha, ablim, ywhaz, sptbn, h2afz, tgfb 1, 18 s and wrnip genes was analyzed. Using the NormFinder program, the most stable genes are as follows: h2afz for the B6D2F-1 and C57BL/6 strains; sptbn for ICR; h2afz for KOSOM and CZB cultures of B6D2F-1 and C57BL/6 strain-derived embryos; wrnip for M16 culture of B6D2F-1 and C57BL/6 strain-derived embryos; ywhaz, tgfb1, $18 \mathrm{~s}, 18 \mathrm{~s}, y$ whaz, and h2afz for zygote, 2-cell, 4-cell, 8-cell, molular, and blastocyst embryonic stages cultured in KSOM medium, respectively; h2afz, wrnip, wrnip, h2afz, ywhaz, and ablim for zygote, 2-cell, 4-cell, 8-cell, molular, and blastocyst stage embryos cultured in CZB medium, respectively; 18 s, h2afz, h2afz, actb, h2afz, and wrnip for zygote, 2-cell, 4-cell, 8-cell, molular, and blastocyst stage embryos cultured in M16 medium, respectively.
\end{abstract}

Conclusions: These results demonstrated that candidate reference genes for normalization of target gene expression using RT-qPCR should be selected according to mouse strains, developmental stage, and culture conditions.

Keywords: RT-PCR, Reference gene, Mouse, Preimplantation embryos, Gene expression

\section{Background}

The culture media used for in vitro propagation of mouse preimplantation embryos plays an important role in maintaining their efficacy and survival rates. Extensive efforts to establish appropriate culture conditions has led to the development of media such as the modified version of Whittingham's original medium 16 \{M16; [1]\}, Chatot-Ziomek-Bavister [CZB; [2]], and Potassium Simplex Optimized Medium \{KSOM; [3]\} for in vitro culture of mouse preimplantation embryos. These culture media contain seven inorganic ions: $\mathrm{Na}^{+}$,

\footnotetext{
*Correspondence: jhkim541@konkuk.ac.kr
Department of Animal Biotechnology, KonKuk University, Seoul 143-701,

* Correspondence: jhkim541@konkuk.ac.kr
Department of Animal Biotechnology, KonKuk University, Seoul 143-701, Republic of Korea
}

(c) 2014 Jeong et al.; licensee BioMed Central Ltd. This is an Open Access article distributed under the terms of the Creative Commons Attribution License (http://creativecommons.org/licenses/by/4.0), which permits unrestricted use, distribution, and reproduction in any medium, provided the original work is properly credited. The Creative Commons Public Domain Dedication waiver (http://creativecommons.org/publicdomain/zero/1.0/) applies to the data made available in this article, unless otherwise stated.
$\mathrm{K}^{+}, \mathrm{Cl}^{-}, \mathrm{Ca}^{2+}, \mathrm{Mg}^{2+}, \mathrm{SO}_{4}^{2-}$, and $\mathrm{PO}_{4}^{2-}[4]: \mathrm{M} 16$ was formulated in the 1970s, whereas, in the late 1980s, CZB and KSOM media were first developed in order to overcome 2-cell blocks, which are sensitive to osmolarity $[5,6]$. Therefore, these media had much lower osmolalities than M16 medium, mainly due to lower inorganic ion concentrations. In contrast, the concentration of $\mathrm{KCl}$, sodium lactate, sodium pyruvate, and glucose were higher in M16 than KSOM. However, M16 has a lower concentration of $\mathrm{KH}_{2} \mathrm{PO}_{4}, \mathrm{NaCl}$, and antibiotics. Also, M16 has no ethylenediaminetetraacetic acid (EDTA) or L-Glutamine. EDTA was shown to affect embryonic development by inhibiting glycolysis at the two-cell stage, thereby preventing the premature stimulation of glycolysis $[7,8]$. In mice, 
the potential for embryonic development during in vitro culture may differ among strains. For example, the ability of one-cell mouse embryos to develop into blastocysts in vitro has been shown to be a function of mouse strains, media components, and culture conditions [9-12]. In this regard, there is a need to assess the relative roles of the mouse strain background and culture environment in the modification of gene regulation during in vitro culture.

The scarcity of the mRNA amounts obtained from preimplantation embryos has hampered the molecular analysis of preimplantation embryos [13-15]. Recent progress in RNA amplification methods and microarray platforms, including genes unique to preimplantation embryos, allow us to apply global gene expression profiling to the study of preimplantation embryos [16-19]. Initially, the majority of studies focused on gene expression analysis of preimplantation embryos, which were based on conventional reverse-transcriptase polymerase chain reaction (RT-PCR) [20,21]. Compared to conventional RT-PCR, several studies reported that real-time quantitative reverse-transcriptase polymerase chain reaction (RTqPCR), in which data are accurately normalized, is significantly less variable than conventional RT-PCR procedures $[22,23]$. Therefore, it is very important to establish an accurate normalization procedure to control for variability in RT-qPCR data. Generally, glyceraldehyde-3phosphate dehydrogenase (gapdh), beta-actin, and ribosomal RNA are commonly used as internal control RNA. However, it has not been examined systematically whether the amount of mRNA in preimplantation embryos is variable for most genes, including reference genes, due to culture environment, media components, and mouse strains. The differences in reference gene expression among mouse strains during in vitro culture may introduce a considerable bias if the values of the target genes were normalized to the values of inconsistent housekeeping genes. Therefore, in order to quantify the limited quantities of mRNA contained in each embryo, a reference gene with stable expression across preimplantation embryos is required.

The expression stability and validation of reference genes suitable for the normalization of RT-qPCR data have been investigated in detail in various organisms including mouse [24-26], rabbit [27], cat [28], pig [29], bovine [22,30-32], horse [33], and human [34,35]. In gene expression studies on animal preimplantation embryos, normalization is generally accomplished using a single housekeeping gene. In the most recent mouse preimplantation study reported, 12 housekeeping genes were tested across in vitro- vs. in vivo-derived preimplantation embryos, and three (ppia, h2afz, and hprt genes) of them were used for normalization of target gene expression [25]. Although several studies have proven that the expression level of reference genes in different conditions varies, the aim of this study is to investigate the expression profiles of reference genes under different experimental conditions, such as different strain backgrounds (C57BL/6 for inbreed, B6D2F-1 for hybrids, and ICR for outbreed), culture conditions, and different development stages during the preimplantation of mouse embryos. In addition, we focused on the identification and selection of the best stable genes for normalization of gene expression analysis in different developmental stages, culture condition, and strains.

\section{Methods}

Animals

The mice were housed in wire cages at $22 \pm 1^{\circ} \mathrm{C}$ under a 12 L:12D cycle with 70\% humidity and fed ad libitum. All experiments were performed in the Institutional Animal Care and Use Committee at Konkuk University (IACUC approval number: KU12079), Seoul, Korea.

\section{Preparation and procurement of media}

All chemicals used for media preparation were purchased from Sigma Chemical Co. (St. Louis, MO, USA). Embryo culture media, such as M16 [1], was purchased from Sigma and contained no EDTA. CZB [2] and KSOM [3] were purchased from Millipore (St. Charles, MO, USA). Amino acids purchased from Sigma were added to KSOM. Each media composition is described in Additional file 1: Table S1. All embryo manipulations outside the incubator were performed in CZB-HEPES medium (Sigma, USA).

\section{Embryo recovery and culture}

Female ICR, B6D2F-1 and C57B/6 mice (age 6-8 wk) were superovulated by injection of 5 IU of equine chorionic gonadotropin (eCG), followed by the injection of $5 \mathrm{IU}$ of hCG $48 \mathrm{~h}$ later, and then mated with male ICR, B6D2F-1, and C57BL/6 mice. Day 0 of gestation was defined as the day a vaginal plug was found. Plug-positive females were separated for experimentation. Zygotes were obtained by opening the ampulla at $20 \mathrm{~h}$ post-hCG administration using CZB-HEPES medium. Approximately 20 embryos were transferred into a $30-\mu \mathrm{L}$ drop of fresh medium (M16, KSOM, CZB) covered with mineral oil. Embryo culture in each media was performed according to manufacturer's protocols and using 5\% $\mathrm{CO}_{2}$ in atmospheric oxygen at $37^{\circ} \mathrm{C}$. Embryo development rates in vitro under three different culture media are shown in Additional file 2: Table S2. For recovery of in vivo-derived embryo, ICR or B6D2F-1 and C57B/6 female mice (4 to $6 \mathrm{wk}$ old) were superovulated using PMSG/hCG and mated with a proven fertile male of the same strain. One cell, 2 cells, 4 cells, 8 cells, morulae and blastocyst stage embryos were recovered at 18-22, 38-42, 48-52, 64-68, 88-92 and 96-100 hrs after hCG injection, respectively. 
RNA isolation and reverse transcription

Twenty embryos were washed in $\mathrm{Ca}^{+2}$ - and $\mathrm{Mg}^{+2}$-free PBS, snap-frozen in liquid nitrogen, and stored at $-70^{\circ} \mathrm{C}$. mRNA was extracted from groups of embryos using the Dynabeads mRNA Direct Kit (Dynal Ase) according to the manufacturer's instructions $(r=6)$. For reverse transcription, total RNAs in a final volume of $20 \mu \mathrm{L}$ (containing $0.5 \mathrm{mg}$ oligo-dT, RT buffer [1×], $10 \mathrm{mM}$ dithiothreitol, and $10 \mathrm{mM}$ dNTP) was subjected to reverse transcription at $37^{\circ} \mathrm{C}$ for $50 \mathrm{~min}$, followed by $70^{\circ} \mathrm{C}$ for $15 \mathrm{~min}$, and products were stored at $4^{\circ} \mathrm{C}$ until use.

\section{Selection of reference genes and primer design}

Reference genes were chosen from those used routinely in studies of pre-implantation embryonic stages [11,36,37]. Other potentially suitable reference genes were selected among those used in published literature on the reproductive system (Table 1) [38-41]. Whenever possible, primers fulfilled the following recommended criteria: amplicon length of $80 \mathrm{bp}-130 \mathrm{bp}$, location of primers on two different exons, primer sequence length of 18-25 bp, melting temperature of $58^{\circ} \mathrm{C} \pm 2^{\circ} \mathrm{C}$ and $\mathrm{GC}$ content of $40 \%-60 \%$. Primer specificity was checked in silico (Primer-BLAST Tool from http://www.ncbi. nlm.nih.gov/tools/primer-blast/). All oligonucleotides were supplied unmodified and desalted (Cosmogenetech, Korea).

\section{Real-time quantitative reverse transcriptase PCR (RT-qPCR)}

The PCR reactions were performed according to the instructions of the real-time PCR machine manufacturer (ABI 7800, Applied Biosystems, Foster City, CA). The threshold cycle $(\mathrm{Ct})$ value represents the cycle number at which sample fluorescence rises to a statistically significant level above the background. Each well contained $1 \mu \mathrm{L}$ of a 10 -fold dilution of cDNA, $10 \mu \mathrm{L}$ of $2 \times$ Maxima $^{\oplus}$ SYBR Green/ROX qPCR Master Mix (Thermo Scientific
Fermentas, Göteborg, Sweden), $2 \mu \mathrm{L}$ of each primer 1 $3 \mu \mathrm{M}$ and $7 \mu \mathrm{L}$ water. We optimized qPCR conditions on the $\mathrm{ViiA}^{\mathrm{TM}} 7$ real-time PCR machine according to manufacturer's instructions and by testing different concentrations of primers and templates. The PCR program was as follows: denaturation $\left(95^{\circ} \mathrm{C}\right.$ for $\left.10 \mathrm{~min}\right)$, amplification and quantification repeated 40 times $\left(95^{\circ} \mathrm{C}\right.$ for $10 \mathrm{sec}$, $55-60^{\circ} \mathrm{C}$ for $30 \mathrm{sec}$, and $72^{\circ} \mathrm{C}$ for $30 \mathrm{sec}$ with a single fluorescent measurement), melting curve analysis (65 $95^{\circ} \mathrm{C}$, with a heating rate $0.2^{\circ} \mathrm{C} / \mathrm{sec}$ and continuous fluorescence measurement), and final cooling to $12^{\circ} \mathrm{C}$.

We confirmed the amplification of specific RT-qPCR products by performing a melting-curve step at the end of each run. Serial dilution curves for each primer allowed us to calculate RT-qPCR efficiencies. The 10-fold diluted cDNA that was used for all the amplifications was within the linear dynamic range of the calibration curve - between 1- and 1000-fold dilution. Across all the assays, none of the quantification cycle $(\mathrm{Cq})$ values were higher than 44. No-template and no-reverse transcription controls were run to determine any contamination or the generation of primer dimers. All amplifications were run in triplicate, and any doubtful curves were excluded. To minimize technical variation between samples through different runs, we preferred the sample maximization method, i.e., a run contained all the samples for one gene of interest respective to one reference gene.

\section{Statistical analysis}

GenEX qPCR data analysis software (Lotsgatan, Göteborg, Sweden) was used for implementation of quality controls and the calculation of optimal endogenous controls. This program uses the comparative $\mathrm{Ct}$ method for relative quantitative analysis, and the results are expressed as a fold change of expression levels. The mean value of triplicates was applied for all calculations. Medians were used to replace missing values that occurred due to inconsistencies between replicates rather than from

Table 1 Primer sets used in this study

\begin{tabular}{|c|c|c|c|c|c|}
\hline Gene name & Accession number & Primer sequences (forward/reverse) & $\operatorname{Tm}\left({ }^{\circ} \mathrm{C}\right)$ & Amplication length & $\begin{array}{c}\text { Amplification } \\
\text { efficacy (\%) }\end{array}$ \\
\hline h2afz & NM_016750 & GTGGACTGTATCTCTGTGAA/GGTTGGTTGGAAGGCTAA & 60 & 89 & 92.1 \\
\hline sdha & NM_023281 & ATTCATTGTCTACTTCTCACT/AGGGTTTATTTGGCTTACA & 58 & 108 & 90.6 \\
\hline $\operatorname{tgfb} 1$ & NM_011577 & TATACTGAGACACCTTGG/GTGATAGTCCTGAATAATTTG & 55 & 83 & 97.2 \\
\hline gapdh & NM_008084 & AGTGGCAAAGTGGAGATT/GTGGAGTCATACTGGAACA & 60 & 83 & 91.5 \\
\hline actb & NM_007393 & ATCTTCCGCCTTAATACT/GCCTTCATACATCAAGTT & 56 & 98 & 90.7 \\
\hline sptbn & NM_175836 & TCTAATGGTTACTTGCTTGT/CAATAGTTACAGTGACAGAGA & 55 & 101 & 91.2 \\
\hline ablim & NM_178688 & GTATTCAGTGTTCACAGT/AATAGCATTAACCAGTAAGA & 55 & 106 & 90.1 \\
\hline ywhaz & NM_001253807 & CAGTAGATGGAGAAAGATTTGC/GGGACAATTAGGGAAGTAAGT & 60 & 92 & 93.5 \\
\hline wrnip & NM_030215 & ATGAGTAGGATGCTTGTA/TAACCACCTCCATCTATG & 56 & 130 & 91.6 \\
\hline $18 \mathrm{~s}$ & X00686 & CGCCGCTAGAGGTGAAATTCT/CGAACCTCCGACTTTCGTTCT & 60 & 102 & 93.6 \\
\hline
\end{tabular}


low expression. To measure the expression stability of the candidate endogenous control genes, the commonly used program NormFinder was employed. All data are expressed as means $\pm \mathrm{SD}$.

\section{Results}

\section{Selection of ten reference genes}

For RT-qPCR analysis, total RNA was extracted from 20 zygotes or embryos. To identify the best reference genes for gene expression studies in mouse preimplantation embryos, an RT-qPCR assay based on large amounts of transcriptome data from the mammalian preimplantation embryos was designed for the transcription profiling of the ten genes (actb, gapdh, sdha, ablim, ywhaz, sptbn, h2afz, tgfb1, $18 \mathrm{~s}$ and wrnip; Table 1). The specificity of the amplifications was confirmed by the presence of a single band of the expected size for each primer pair in agarose gels following electrophoresis, and by visualizing the single-peak melting curves of the PCR products (Additional file 3: Figure S1). The melting temperatures of all PCR products are shown in Table 1.

The cycle threshold values of candidate genes in different experimental subsets/conditions showed in Additional file 4: Table S3. All the genes tested in this study, using the NormFinder analysis, presented gene stability values (SD-value) acceptable enough for them to qualify as potential reference genes in both mouse strains and culture media. Among them, in all different experimental conditions including culture conditions, development stages and strains, the $18 \mathrm{~s}$ gene had a lower average $\mathrm{Ct}$ value, whereas the $t g f b 1$ gene had a higher average $\mathrm{Ct}$ value. The RT-qPCR test suggested that $t g f b 1$ should be selected as an internal reference gene when analyzing a high-abundance target gene, while $18 s$ can serve as an internal reference gene when analyzing a low-abundance target gene.

\section{Validation of reference genes}

Gene expression during the 2-cell, 4-cell, 8-cell, morulae, and blastocyst embryonic stages were analyzed in three differently derived mouse preimplantation embryos grown under three different culture media, and in the in vivo-derived embryos (Figure 1; Additional file 5: Figure S2 and Additional file 6: Figure S3). The pairwise comparison of all the potential reference genes (actb, gapdh, sdha, ablim, ywhaz, sptbn, h2afz, tgfb1, $18 s$ and wrnip) calculated using NormFinder resulted in SD-values above 1.0 for all except the $h 2 f z$ gene, which showed 0.92 and 0.84 for the B6D2F-1 and C57BL/6 strains, respectively (Figure 2). In the ICR strains, however, both $h 2 a f z$ and ablim genes were below the SD-value cut-off of 1.0.

\section{NormFinder analysis of in Vivo vs. in vitro derived embryos}

We used NormFinder analysis as a model-based approach to identify the optimal reference genes among a set of candidates. A lower average expression stability value indicates that the gene expression is more stable. NormFinder ranks all reference gene candidates based on intra- and inter-group variations and combines both results into a stability value for each reference gene candidate [42]. In B6D2F-1 embryos, $h 2 a f z$, $a c t b$, and $t g f b 1$ are ranked as good reference genes in M16 and KSOM media, whereas $h 2 a f z$ and $18 s$ are ranked as good reference genes in CZB (Table 2). Even though $a c t b$ and $t g f b 1$ are the most stably expressed genes across strains cultured in M16 and KSOM media, these reference genes did not fulfill the stability criteria in CZB medium. By NormFinder analysis, the recommended comprehensive ranking of the stability of gene expression in the in vivoderived embryos was determined as $h 2 a f z>$ gapdh $>$ tgfb1 > wrnip > sptbn > $18 s>$ ablim $>y$ whaz $>$ sdha $>a c t b$. In $\mathrm{C} 57 \mathrm{~B} / 6$ embryos, $h 2 a f z$ is the most suitable gene for studies in the three different media tested and in the in vivo-derived embryos. Of note, sdha in KSOM media is the most suitable reference gene, whereas this reference gene was identified as the least stable gene for CZM and M16 media, and in vivo-derived embryos (Table 2). The average gene expression stability in order of most stable to least stable genes for in vivo-derived embryos was determined as $h 2 a f z>$ gapdh $>18 s>$ wrnip $>$ tgfbl $>$ sptbn $>a c t b>a b l i m>y w h a z>$ sdha. In ICR embryos, the gene with the most stable expression for in vitro- and in vivo-derived embryos was $h 2 a f z$ (Table 2). Of note, the gene stability of in vivo-derived embryos contrasted with in vitro culture-derived embryos: most of the reference genes, except sdha, showed stable expression. In conclusion, the best reference gene for in vitro- or in vivo-derived embryos is $h 2 a f z$, regardless of culture media used.

\section{NormFinder analysis of inbred vs. hybrid or outbred embryos}

h2afz was found to be most stable in B6D2F-1 and C57BL/6 embryos cultured in KSOM and CZB media (Table 2), while gapdh was the best reference gene for analyzing B57BL/6 (Table 2) and ICR strains (Table 2) cultured in M16 and KSOM media. The wrnip gene was the most stable for evaluating the B6D2F-1 strain cultured in M16 medium (Table 2) and for the ICR strain propagated in CZB and M16 media (Table 2). The albim and sptbn genes proved to be the most stable. On the other hand, ablim exhibited poor stability in B6D2F-1 and B57BL/6 cultured in M16 medium, and CZB or M16 media, respectively (Figure $3 \mathrm{~B}$ and Additional file 7: Figure S4B and C). The other genes that consistently ranked poorly included sdha for B6D2F-1 in KSOM and 


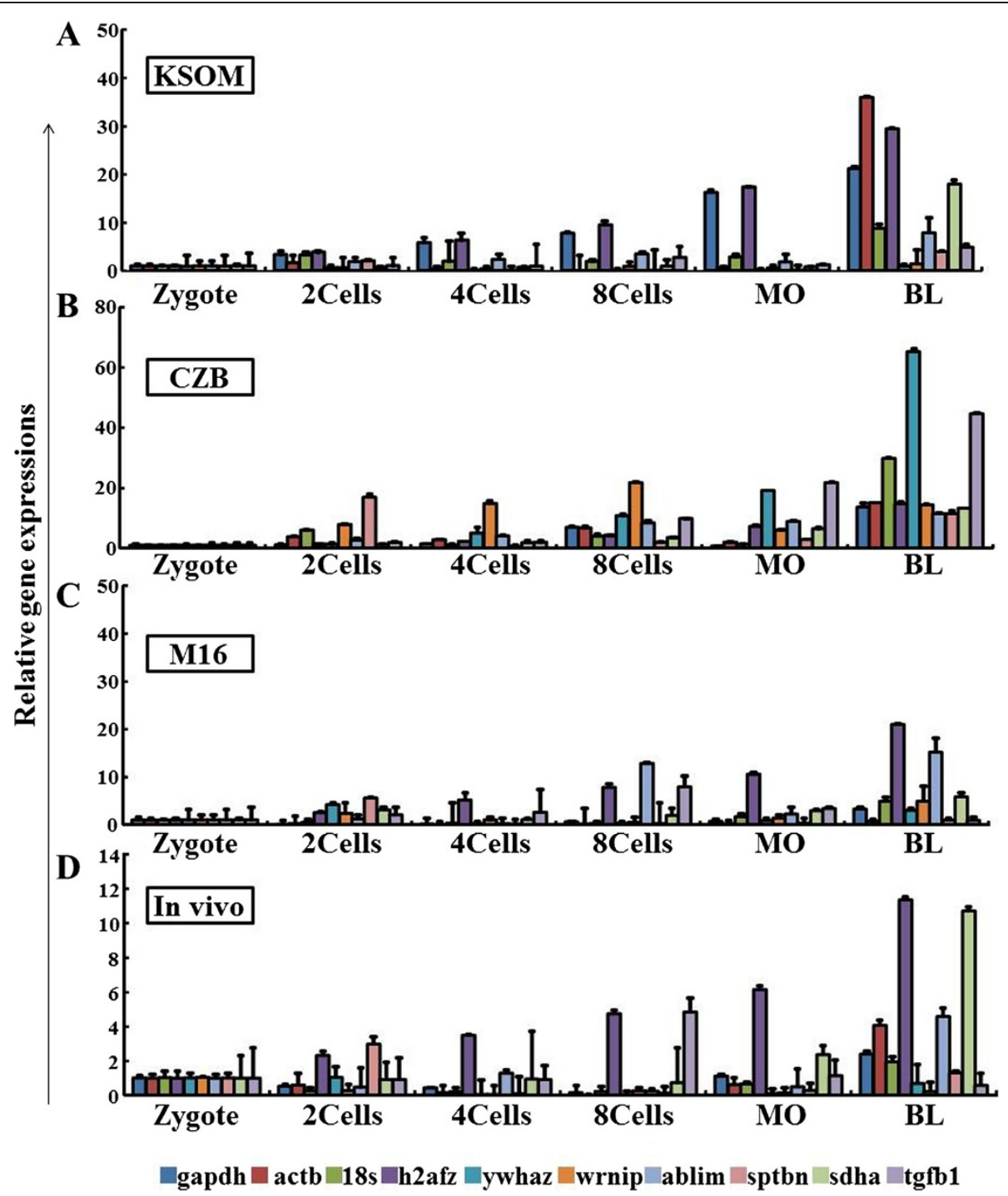

Figure 1 Transcript levels of selected reference genes in the ICR mouse-derived preimplantation stage embryos. Transcription levels of ten housekeeping genes shown for KSOM- (A), CZB- (B), M16- (C), and in vivo (D)-derived embryos. The mRNA expression level at zygote stage was measured as a control to calculate the relative amounts in the different stages.

M16 media (Table 2), $18 s$ for C57BL/6 and ICR cultured in KSOM and CZB, respectively (Table 2). Also, the $a c t b$ and wrnip genes were least stable in ICR strain embryos cultured in KSOM and M16 media (Table 2). Even though gapdh and actb for the ICR and B6D2F-1 strains in KSOM medium emerged as the most stably expressed, consolidated evaluation under different conditions estimated that these genes were least stable in the B6D2F-1 and ICR strains (Table 2). When evaluated across three different strains, h2afz (B6D2F-1, C57BL/6, ICR), $18 \mathrm{~s}$ (B6D2F-1), sptbn (B6D2F-1), gapdh (C57BL/6), ablim (ICR), and $a c t b$ (C57BL/6, ICR) in CZB medium are the most stable, whereas $18 \mathrm{~s}$ (ICR), sptbn (ICR), actb (B6D2F-1) and ablim (B6D2F-1) have been excluded as good candidate reference genes. The results showed that the best-ranked reference genes differed across culture conditions or mouse strains.

Ranking order of reference genes according to developmental stages of preimplantation embryos At the 2-cell stage

the ranking order of reference genes in KSOM medium are wrnip > tgfb1 > ablim > h2afz> 18 s > ywhaz > sptbn $>a c t b>$ gapdh $>$ sdha (Figure 3A); h2afz $>a c t b>$ wrnip $>$ sdha $>$ $18 s>$ sptbn $>$ gapdh $>y$ whaz $>$ ablim $>t g f b 1$ for CZB medium (Table 3); h2afz $>$ sptbn $>y$ whaz $>$ sdha $>$ wrnip $>$ $18 s>\operatorname{tgfb} 1>$ gapdh $>$ ablim $>a c t b$ for M16 medium (Table 3); tgfb1 $>$ ywhaz> $18 \quad s>$ sptbn $>$ ablim $>h 2 a f z>$ $a c t b>$ sdha $>$ gapdh $>$ wrnip for in vivo embryos (Table 3). Unlike the in vitro culture system, wrnip, h2afz, and tgfb1 

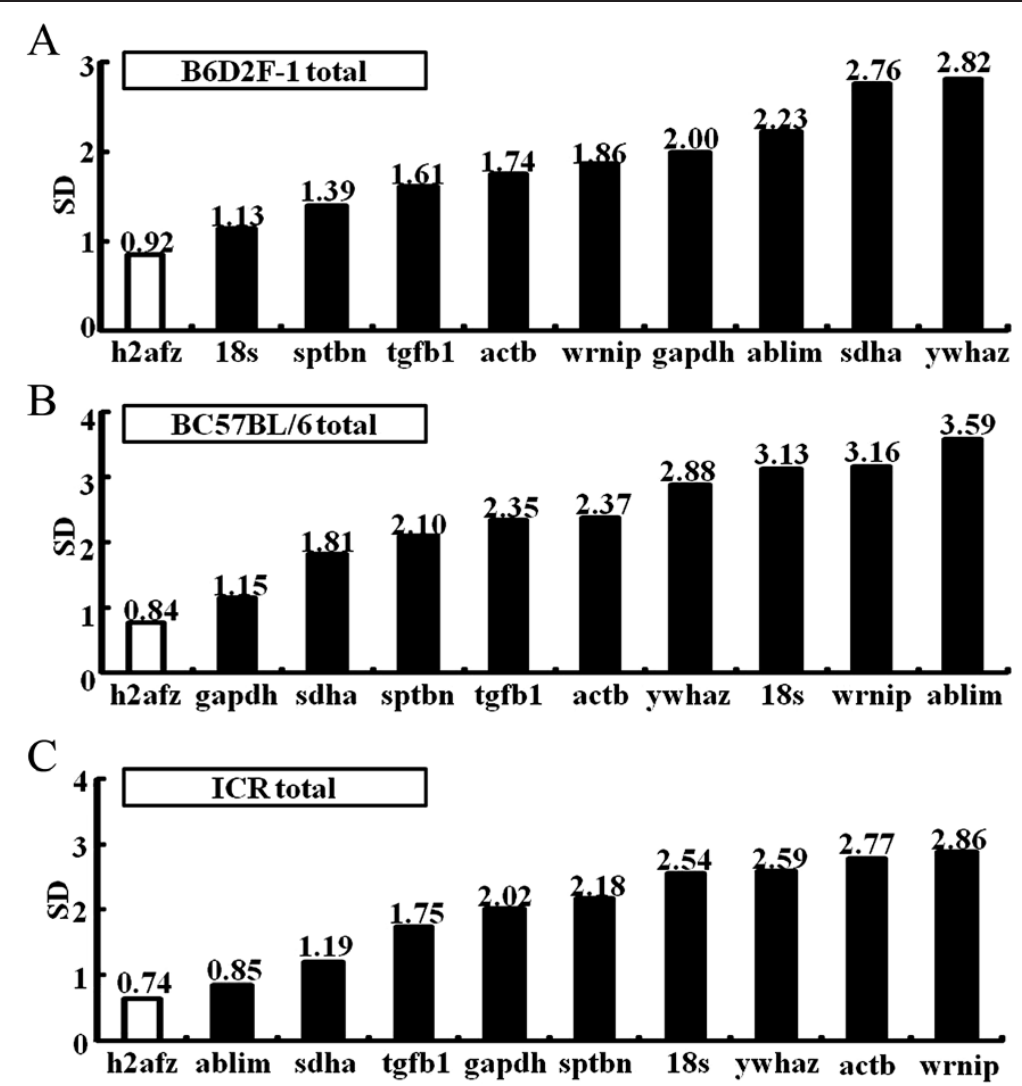

Figure 2 The expression stability of reference genes in pre-implantation embryos (from zygote to blastocyst stages) derived from three different mouse strain backgrounds were analyzed by the NormFinder program. Average gene expression stability values of reference genes are shown for B6D2F-1- (A), C57BL/6- (B) and ICR (C)-derived embryos. The most stable genes are on the left and the least stable genes on the right along the $\mathrm{X}$-axis. The experiments were performed in triplicate; data shown represent the mean of three independent experiments.

are the least stable among the reference genes in the in vivo-derived embryos. Also, when evaluated across three different strains, sptbn is the most stable gene in the B6D2F-1 and C57BL/6 strains; ablim is the least stable gene, although it is the most stable gene in the ICR strains (Table 4 and Additional file 7: Figure S4, Additional file 8: Figure S5 and Additional file 9: Figure S6).

\section{At the 4-cell stage}

The present study identified reliable reference genes among ten candidate genes for normalization of RT-qPCR data in mouse preimplantation embryos during the 4-cell development stage: wrnip $>h 2 a f z>$ ablim $>$ sptbn $>\operatorname{tgfb} 1>$ $18 s>y w h a z>s d h a>a c t b>$ gapdh for KSOM (Figure 3B); $h 2 a f z>a c t b>y w h a z>18 \quad s>s d h a>s p t b n>$ wrnip $>$ gapdh $>$ ablim $>$ tgfb1 for CZB (Table 3); h2afz $>$ sptbn $>$ sdha $>$ ywhaz $>\operatorname{tgfb} 1>$ gapdh $>$ wrnip $>18 s>$ ablim $>a c t b$ for M16 (Table 3); $18 s>$ sptbn $>y$ whaz $>$ gapdh $>h 2 a f z>a c t b>$ tgfbl $>$ sdha $>$ ablim $>$ wrnip for in vivo-derived embryos (Table 3). Notably, wrnip and $18 s$ in KSOM and in vivo-embryos are most stable, whereas these genes in the in vivo- and M16-derived embryos did not show a highly stable expression pattern. Although sdha (KSOM and $\mathrm{CZB}$ ), ablim (CZB, M16) and gapdh (KSOM ,CZB and M16) were the least stable genes under the different culture conditions tested, sdha (B6D2F-1), albim $(\mathrm{C} 57 \mathrm{Bl} / 6)$ and gapdh (ICR) displayed a stable expression pattern in the corresponding strain backgrounds (Table 4 and Additional file 7: Figure S4, Additional file 8: Figure S5 and Additional file 9: Figure S6).

\section{At the 8-cell stage}

Next, we identified reference genes for 8-cell stages using KSOM-, CZB-, and M16-derived embryos or in vivo-derived embryos. The order of gene stability amongst the 8-cell stage embryos was $h 2 a f z>s p t b n>t g f b 1>$ gapdh $>$ ablim $>y$ whaz $>$ wrnip $>s d h a>18 s>a c t b$ for KSOM (Table 3); actb $>$ h2afz $>y$ whaz $>$ sdha $>18 s>$ wrnip $>$ sptbn $>$ gapdh $>$ ablim $>$ tgfb1 for CZB (Figure 3C); ywhaz > sptbn > sdha > h2afz > $18 s>$ gapdh $>$ tgfb $1>$ wrnip > ablim >actb for M16 (Table 3) and $18 s>h 2 a f z>$ gapdh $>y$ whaz $>$ tgfb $1>$ sptbn $>$ ablim $>$ sdha $>$ wrnip $>a c t b$ for in vivo-derived embryos (Table 3). Unlike the other developmental stages, there was significant discrepancy in 
the ranking order of reference genes under each different culture conditions. When examined across three different strains, sptbn, sdah, tgfb1, and $y w h a z$ were the most stable in B6D2F1 strains and ywaz and sptbn had highly stable expression patterns in the C57BL/6 strain background. However, in ICR strains, gapdh is only stable gene (Table 4 and Additional file 7: Figure S4, Additional file 8: Figure S5 and Additional file 9: Figure S6).

\section{At morulae stages}

ywhaz $>$ ablim $>$ h2afz $>$ sptbn $>$ wrnip $>18 \quad s>$ gapdh $>$ tgfbl $>$ sdh $a>a c t b$ were found to be the most stably expressed reference genes when mouse preimplantation

Table 2 Expression stability and ranking of ten reference genes in each strains derived-embryos analyzed using NormFinder software

\begin{tabular}{|c|c|c|c|c|c|c|}
\hline \multirow[t]{2}{*}{ Strains } & \multirow[t]{2}{*}{ Ranking } & \multicolumn{4}{|c|}{ In vitro } & \multirow[t]{2}{*}{ In vivo } \\
\hline & & KSOM & CZB & M16 & Total & \\
\hline B6D2F-1 & & h2afz & h2afz & wrnip & h2afz & h2afz \\
\hline $\mathrm{BC} 57 \mathrm{BL} / 6$ & 1 & h2afz & h2afz & gapdh & h2afz & h2afz \\
\hline ICR & & gapdh & ablim & sptbn & h2afz & sptbn \\
\hline $\mathrm{B} 6 \mathrm{D} 2 \mathrm{~F}-1$ & & actb & $18 \mathrm{~s}$ & $18 \mathrm{~s}$ & $18 \mathrm{~s}$ & gapdh \\
\hline BC57BL/6 & 2 & sdha & gapdh & h2afz & gapdh & gapdh \\
\hline ICR & & h2afz & actb & h2afz & ablim & h2afz \\
\hline $\mathrm{B} 6 \mathrm{D} 2 \mathrm{~F}-1$ & & tgfb1 & sptbn & h2afz & sptbn & tgfb1 \\
\hline $\mathrm{BC} 57 \mathrm{BL} / 6$ & 3 & tgfb1 & actb & sptbn & sdha & $18 \mathrm{~s}$ \\
\hline ICR & & ablim & h2afz & ablim & sdha & ywhaz \\
\hline $\mathrm{B} 6 \mathrm{D} 2 \mathrm{~F}-1$ & & ablim & gapdh & gapdh & tgfb1 & wrnip \\
\hline BC57BL/6 & 4 & gapdh & tgfb1 & actb & sptbn & wrnip \\
\hline ICR & & $18 \mathrm{~s}$ & sdha & sdha & tgfb1 & ablim \\
\hline B6D2F-1 & & sptbn & sdha & ablim & actb & sptbn \\
\hline $\mathrm{BC} 57 \mathrm{BL} / 6$ & 5 & actb & sptbn & sdha & tgfb1 & tgfb1 \\
\hline ICR & & sdha & tgfb1 & tgfb1 & gapdh & actb \\
\hline $\mathrm{B} 6 \mathrm{D} 2 \mathrm{~F}-1$ & & $18 \mathrm{~s}$ & wrnip & tgfb1 & wrnip & $18 \mathrm{~s}$ \\
\hline $\mathrm{BC} 57 \mathrm{BL} / 6$ & 6 & sptbn & $18 \mathrm{~s}$ & ywhaz & actb & sptbn \\
\hline ICR & & sptbn & gapdh & $18 \mathrm{~s}$ & sptbn & $18 \mathrm{~s}$ \\
\hline B6D2F-1 & & wrnip & $\operatorname{tgfb} 1$ & actb & gapdh & ablim \\
\hline BC57BL/6 & 7 & ablim & sdha & wrnip & ywhaz & actb \\
\hline ICR & & tgfb1 & ywhaz & actb & $18 \mathrm{~s}$ & tgfb1 \\
\hline $\mathrm{B} 6 \mathrm{D} 2 \mathrm{~F}-1$ & & ywhaz & ywhaz & sptbn & ablim & ywhaz \\
\hline $\mathrm{BC} 57 \mathrm{BL} / 6$ & 8 & ywhaz & ywhaz & $18 \mathrm{~s}$ & $18 \mathrm{~s}$ & ablim \\
\hline ICR & & ywhaz & wrnip & ywhaz & ywhaz & wrnip \\
\hline $\mathrm{B} 6 \mathrm{D} 2 \mathrm{~F}-1$ & & gapdh & actb & ywhaz & sdha & sdha \\
\hline BC57BL/6 & 9 & wrnip & wrnip & tgfb1 & wrnip & ywhaz \\
\hline ICR & & wrnip & sptbn & gapdh & actb & gapdh \\
\hline $\mathrm{B} 6 \mathrm{D} 2 \mathrm{~F}-1$ & & sdha & ablim & sdha & ywhaz & actb \\
\hline BC57BL/6 & 10 & $18 \mathrm{~s}$ & ablim & ablim & ablim & sdha \\
\hline ICR & & actb & $18 \mathrm{~s}$ & wrnip & wrnip & sdha \\
\hline
\end{tabular}

embryos were cultured in KSOM (Figure 3D). The order of stability was $h 2 a f z>y w h a z>\operatorname{tgfb} 1>$ wrnip $>a c t b>s d h a>$ sptbn $>18 s>a b l i m>$ gapdh (Table 3) and h2afz $>$ sptbn $>$ sdha $>$ ywhaz $>$ tgfb $1>$ gapdh $>$ wrnip $>18$ s $>a c t b>a b l i m$ (Table 3) for CZB and M16 media, respectively. For in vivoderived embryos, the most to least stably expressed genes were as follows: $y w h a z>h 2 a f z>18 \quad s>$ gapdh $>$ ablim $>$ sdha $>\operatorname{tg} f b 1>$ sptbn $>a c t b>$ wrnip (Table 3). During these stages, $y w h a z$ is the most stably expressed of the reference genes, while $18 \mathrm{~s}$, ablim and gapdh were the least stable. But, the $y w h a z$ gene was the least stable gene in ICR strains, although it was stably expressed in the B6D2F-1 and $\mathrm{C} 57 \mathrm{Bl} / 6$ strains (Table 4 and Additional file 7: Figure S4, Additional file 8: Figure S5 and Additional file 9: Figure S6).

\section{At the blastocyst stage}

The order of the most stably expressed reference genes to the least stable genes in KSOM, CZB, and M16 media are as follows: ablim $>a c t b>s p t b n>18 \quad s>h 2 a f z>$ ywhaz $>$ wrnip $>$ tgfb $1>$ gapdh $>$ sdha for KSOM medium (Additional file 9: Figure S6E); wrnip $>h 2 a f z>y w h a z>$ $a c t b>s p t b n>s d h a>18 s>t g f b 1>a b l i m>$ gapdh for CZB medium (Table 3); h2afz >tgfb1 > sptbn > ywhaz > gapdh> sdha $>$ wrnip $>18 s>a b l i m>a c t b$ for M16 medium (Table 3): h2afz $>$ ywhaz $>18 \quad s>a c t b>s p t b n>$ gapdh $>$ sdha $>\operatorname{tgfb} 1>$ ablim > wrnip for in vivo blastocyst (Table 3). During this stage, $h 2 a f z$ and $y w h a z$ are the most stably expressed reference genes, whereas wrnip is the least stable gene. Consistent with these results, data for the B6D2F-1 and $\mathrm{C} 57 \mathrm{Bl} / 6$ strains showed that $h 2 a f z$ and $y w h a z$ are the most stably expressed, while the wrnip gene was the most stable in the ICR strain (Table 4 and Additional file 7: Figure S4, Additional file 8: Figure S5 and Additional file 9: Figure S6). Thus, these results showed that culture conditions and mouse strains are the main factors affecting the stable expression of reference genes in the RTqPCR experiments.

\section{Discussion}

RT-qPCR is an invaluable technique for investigating changes in gene expression during preimplantation embryonic stages [43-45]. Since it has be performed on limited quantities of mRNA contained in each embryo, the reliability of this method mainly depends on the use of validated, stably expressed reference genes for the normalization of mRNA expression [46]. However, to the best of our knowledge, no such study on gene expression and stability in different strains cultured under different conditions has been published. The present work was thus undertaken to emphasize the need to validate the expression stability of reference genes in preimplantation embryos using different mouse strains and varied culture conditions. 


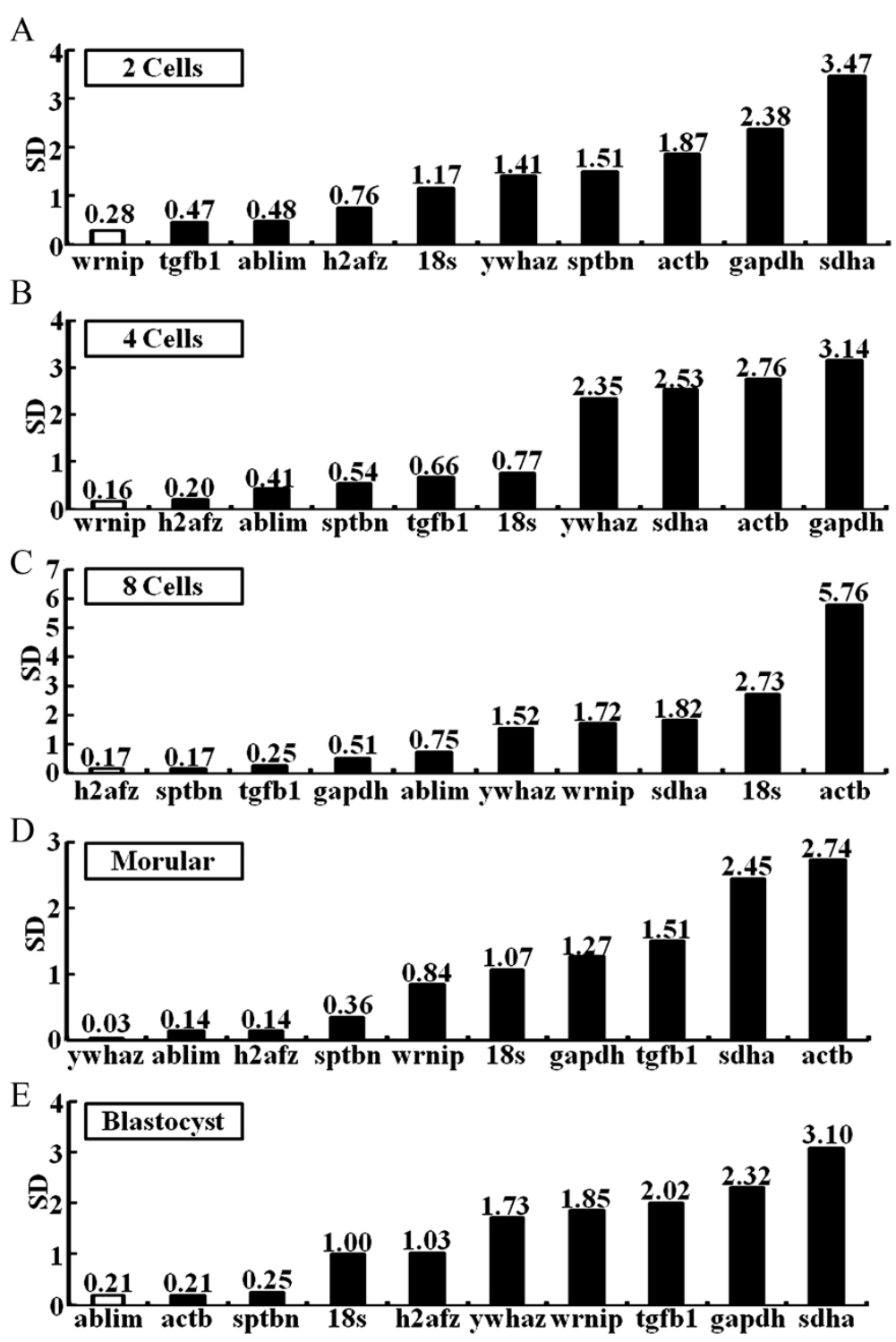

Figure 3 Most stable to least stable gene expression analysis in embryos cultured in KSOM medium based on their expression stability: (A) 2-cell, (B) 4- cell, C) 8-cell, (D) morulae, and (E) blastocyst stages. Data were obtained from A-E. Ranking is based on the principle that gene pairs have stable expression patterns relative to each other and are considered appropriate reference genes. The most stable genes are on the left and the least stable genes on the right along the X-axis. The experiments were performed in triplicate; data shown represent the mean of three independent experiments.

An ideal reference gene is one that is stably expressed within the samples to be compared, regardless of tissue differences, experimental conditions or treatments $[47,48]$. 'Housekeeping' genes are often supposed to have a steady expression pattern, and have been used extensively as reference genes [49]. However, many reports have shown that the expression levels of internal standards, including some housekeeping genes such as gapdh, actb, or $18 \mathrm{~s}$, can alter considerably in response to alterations in the experimental conditions [50-52]. In this study, we also reconfirmed that several of the commonly used reference genes, including gapdh, $18 \mathrm{~s}$ rRNA, and beta-actin, are unsuitable for normalization during in vitro culture of some of mouse strain-derived embryos.

In this study, we selected ten genes (actb, gapdh, sdha, ablim, ywhaz, sptbn, h2afz, tgfb1, $18 s$ and wrnip) because they play different cellular roles: $a c t b$, ablim and sptbn encode cytoskeletal components expressed in various types of cells [53-55]; gapdh encodes an enzyme that catalyzes glycolysis for energy and carbon molecules [56]; ywhaz is implicated in the protection of cells from apoptosis through binding to the pro-apoptotic protein 
Table 3 Ranking of reference genes according to development stages of pre-implantation embryo stages

\begin{tabular}{|c|c|c|c|c|c|c|}
\hline Medium & Ranking & $2 \mathrm{C}$ & $4 C$ & $8 C$ & Mo & $\mathrm{BI}$ \\
\hline$\overline{\mathrm{KSOM}}$ & \multirow{4}{*}{1} & wrnip & wrnip & h2afz & ywhaz & ablim \\
\hline CZB & & h2afz & h2afz & actb & h2afz & wrnip \\
\hline M16 & & h2afz & h2afz & ywhaz & h2afz & h2afz \\
\hline in-vivo & & $\operatorname{tgfb} 1$ & $18 \mathrm{~s}$ & $18 \mathrm{~s}$ & ywhaz & h2afz \\
\hline KSOM & \multirow{4}{*}{2} & $\operatorname{tgfb} 1$ & h2afz & sptbn & ablim & actb \\
\hline CZB & & tgfb1 & tgfb1 & h2afz & ywhaz & h2afz \\
\hline M16 & & sptbn & sptbn & sptbn & sptbn & tgfb1 \\
\hline in-vivo & & ywhaz & sptbn & h2afz & h2afz & ywhaz \\
\hline $\mathrm{KSOM}$ & \multirow{4}{*}{3} & ablim & ablim & $\operatorname{tgfb} 1$ & h2afz & sptbn \\
\hline CZB & & wrnip & ywhaz & ywhaz & $\operatorname{tgfb} 1$ & ywhaz \\
\hline M16 & & ywhaz & sdha & sdha & sdha & sptbn \\
\hline in-vivo & & $18 \mathrm{~s}$ & ywhaz & gapdh & $18 \mathrm{~s}$ & $18 \mathrm{~s}$ \\
\hline KSOM & \multirow{4}{*}{4} & h2afz & sptbn & gapdh & sptbn & $18 \mathrm{~s}$ \\
\hline CZB & & sdha & $18 \mathrm{~s}$ & sdha & wrnip & actb \\
\hline M16 & & sdha & ywhaz & h2afz & ywhaz & ywhaz \\
\hline in-vivo & & sptbn & gapdh & ywhaz & gapdh & actb \\
\hline $\mathrm{KSOM}$ & \multirow{4}{*}{5} & $18 \mathrm{~s}$ & $\operatorname{tgfb} 1$ & ablim & wrnip & h2afz \\
\hline CZB & & $18 \mathrm{~s}$ & sdha & $18 \mathrm{~s}$ & actb & sptbn \\
\hline M16 & & wrnip & $\operatorname{tgfb} 1$ & $18 \mathrm{~s}$ & $\operatorname{tgfb} 1$ & gapdh \\
\hline in-vivo & & ablim & h2afz & tgfb1 & ablim & sptbn \\
\hline $\mathrm{KSOM}$ & \multirow{4}{*}{6} & ywhaz & $18 \mathrm{~s}$ & ywhaz & $18 \mathrm{~s}$ & ywhaz \\
\hline CZB & & sptbn & sptbn & wrnip & sdha & sdha \\
\hline M16 & & $18 \mathrm{~s}$ & gapdh & gapdh & gapdh & sdha \\
\hline in-vivo & & h2afz & actb & sptbn & sdha & gapdh \\
\hline KSOM & \multirow{4}{*}{ 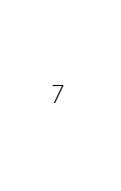 } & sptbn & ywhaz & wrnip & gapdh & wrnip \\
\hline CZB & & gapdh & wrnip & sptbn & sptbn & $18 \mathrm{~s}$ \\
\hline M16 & & tgfb1 & wrnip & $\operatorname{tgfb} 1$ & wrnip & wrnip \\
\hline in-vivo & & actb & $\operatorname{tgfb} 1$ & ablim & tgfb1 & sdha \\
\hline $\mathrm{KSOM}$ & \multirow{4}{*}{8} & actb & sdha & sdha & tgfb1 & tgfb1 \\
\hline CZB & & ywhaz & gapdh & gapdh & $18 \mathrm{~s}$ & $\operatorname{tgfb} 1$ \\
\hline M16 & & gapdh & $18 \mathrm{~s}$ & wrnip & $18 \mathrm{~s}$ & $18 \mathrm{~s}$ \\
\hline in-vivo & & sdha & sdha & sdha & sptbn & tgfb1 \\
\hline $\mathrm{KSOM}$ & \multirow{4}{*}{9} & gapdh & actb & $18 \mathrm{~s}$ & sdha & gapdh \\
\hline CZB & & ablim & ablim & ablim & ablim & ablim \\
\hline M16 & & ablim & ablim & ablim & actb & ablim \\
\hline in-vivo & & gapdh & ablim & wrnip & actb & ablim \\
\hline KSOM & \multirow{4}{*}{10} & sdha & gapdh & actb & actb & sdha \\
\hline CZB & & tgfb1 & $\operatorname{tgfb} 1$ & $\operatorname{tgfb} 1$ & gapdh & gapdh \\
\hline M16 & & actb & actb & actb & ablim & actb \\
\hline in-vivo & & wrnip & wrnip & actb & wrnip & wrnip \\
\hline
\end{tabular}

Table 4 Stability rankings of ten endogenous reference genes according to development stages of preimplantation embryo stages in each mouse strains

\begin{tabular}{|c|c|c|c|c|c|c|}
\hline Strains & Ranking & $2 C$ & $4 C$ & $8 C$ & Mo & $\mathrm{BI}$ \\
\hline B6D2F-1 & & sptbn & sdha & sptbn & h2afz & h2afz \\
\hline C57BL/6 & 1 & sptbn & ablim & ywhaz & ablim & ywhaz \\
\hline$I C R$ & & ablim & gapdh & gapdh & tgfb1 & ablim \\
\hline B6D2F-1 & & ywhaz & sptbn & sdha & gapdh & sptbn \\
\hline C57BL/6 & 2 & wrnip & sptbn & sptbn & sptbn & sptbn \\
\hline$I C R$ & & sptbn & sptbn & actb & wrnip & wrnip \\
\hline B6D2F-1 & & sdha & ywhaz & tgfb1 & ywhaz & sdha \\
\hline C57BL/6 & 3 & sdha & h2afz & ablim & wrnip & ablim \\
\hline ICR & & ywhaz & $18 \mathrm{~s}$ & ablim & h2afz & sptbn \\
\hline B6D2F-1 & & wrnip & h2afz & ywhaz & ywhaz & sdha \\
\hline C57BL/6 & 4 & actb & wrnip & sdha & h2afz & gapdh \\
\hline ICR & & wrnip & wrnip & sdha & gapdh & gapdh \\
\hline B6D2F-1 & & h2afz & tgfb1 & h2afz & sptbn & gapdh \\
\hline C57BL/6 & 5 & h2afz & gapdh & $18 \mathrm{~s}$ & gapdh & h2afz \\
\hline ICR & & gapdh & sdha & h2afz & ywhaz & $18 \mathrm{~s}$ \\
\hline B6D2F-1 & & gapdh & gapdh & $18 \mathrm{~s}$ & sdha & tgfb1 \\
\hline C57BL/6 & 6 & gapdh & ywhaz & gapdh & ywhaz & $18 \mathrm{~s}$ \\
\hline$I C R$ & & h2afz & h2afz & sptbn & $18 \mathrm{~s}$ & actb \\
\hline B6D2F-1 & & $18 \mathrm{~s}$ & wrnip & gapdh & $18 \mathrm{~s}$ & ywhaz \\
\hline C57BL/6 & 7 & $18 \mathrm{~s}$ & sdha & actb & sdha & sdha \\
\hline ICR & & sdha & actb & ywhaz & sptbn & sdha \\
\hline B6D2F-1 & & $\operatorname{tgfb1}$ & $18 \mathrm{~s}$ & wrnip & wrnip & $18 \mathrm{~s}$ \\
\hline C57BL/6 & 8 & ablim & actb & wrnip & actb & actb \\
\hline ICR & & $18 \mathrm{~s}$ & ywhaz & wrnip & actb & h2afz \\
\hline B6D2F-1 & & actb & ablim & ablim & actb & actb \\
\hline C57BL/6 & 9 & $\operatorname{tgfb1}$ & $18 \mathrm{~s}$ & h2afz & tgfb1 & wrnip \\
\hline$I C R$ & & actb & tgfb1 & $18 \mathrm{~s}$ & ablim & ywhaz \\
\hline B6D2F-1 & & ablim & actb & actb & ablim & ablim \\
\hline C57BL/6 & 10 & ywhaz & $\operatorname{tgfb} 1$ & $\operatorname{tgfb} 1$ & $18 \mathrm{~s}$ & tgfb1 \\
\hline ICR & & tgfb1 & ablim & $\operatorname{tgfb} 1$ & sdha & $\operatorname{tgfb} 1$ \\
\hline
\end{tabular}

[57]; sdha encodes the enzyme that catalyzes oxidation in the succinate pathway [58]; h2afz encodes a component of the nucleosome structure of the chromosomal fiber [59]; $18 s$ encodes a part of the ribosomal RNA [60]; tgfb1 is a multifunctional component that controls proliferation and differentiation in several cell types [61]; and wrnip interacts with the $\mathrm{N}$-terminus of the Wener protein containing the exonuclease domain [62]. KSOM and CZB media were chosen because they were optimized for inbred and outbred strains [3]. M16 medium, on the other hand was chosen, because it had higher osmolalities than KSOM and CZB media: CZB medium differs from the M16 medium, since it contains a high lactate:pyruvate ratio, $1 \mathrm{mM}$ glutamine and lacks glucose. In addition, the B6D2F-1, C57BL/6, and 
ICR strains were chosen because these strains are welldefined and frequently used in embryological research.

In this study, we compared the candidate genes and established a stability ranking using the NormFinder software. The stability of gene expression and, therefore, the choice of reference gene for ICR strains varied considerably based on the culture media used. The most stable reference genes for KSOM, M16, and CZB media or in vivo embryos are the gapdh, ablim, and sptbn genes, respectively (Additional file 8: Figure S5). The gene $h 2 a f z$ was the most stable reference for B6D2F-1, except that wrnip was more stable than $h 2 a f z$, when cultured in M16 medium (Table 2). In the B6D2F-1 and C57BL/6 strains (Table 2), the best stable reference for $\mathrm{CZB}$ medium is $h 2 a f z$, whereas ablim is the best suitable gene for the ICR strain (Table 2). In the mouse embryos cultured in KSOM medium, the results of NormFinder software indicate that the $h 2 a f z$ gene is the most stable reference gene in the zygote and 8-cell stages, whereas wrnip is the most stable reference gene in the 2-cell and 4-cell stages, ywhaz for the morulae stage, and ablim for the blastocyst stage (Figure 3). In the mouse embryos cultured in CZB medium, $18 \mathrm{~s}$ is the most stable reference gene in the zygote stage, whereas $h 2 a f z$ is the most stable in the 2-cell, 4-cell and morulae stages, $a c t b$ for the 8-cell stage, and wrnip for the blastocyst stage (Table 3). In M16 medium, ywhaz is the most stable housekeeping gene in the zygote and 8-cell stages. The $h 2 a f z$ gene is the most stable of the reference genes in the 2-cell, 4-cell, morulae, and blastocyst stages (Table 3 ). This difference may be caused by culture media or the difference in developmental stages. Also, the reference gene expression levels in each of the developmental stages were shown in the different mouse strains tested (Figure 1; Additional file 5: Figure S2 and Additional file 6: Figure S3). Taken together, our observed data suggested that candidate reference genes to normalize and analyze target gene expression should be selected according to mouse strain, culture conditions, and developmental stages of the embryos.

The majority of gene expression studies on preimplantation embryos have been performed using only one housekeeping gene [63-65]. Contrary to our results, Chang et al. [66] reported significantly lower stability values for four reference genes (sdha, sptbn, ablim and wrnip); for example, sptbn had a higher stability value in our experiments. The differences in expression stability may be the result of different media or developmental stages analyzed in the compared experiments. The second observed difference relates to the ranking of the stability of the reference genes; for example, wrnip was found to be one of the two most stable genes in a recent study, but is one of the least stable genes in our study. The regulation of reference genes is not only variety/cultivar specific, but may also be developmental stage- or strain-specific and influenced by the experimental conditions [67-69]. Some genes have a relatively constant expression level across tissues while others do not [23]. This calls for validation and selection of appropriate housekeeping genes for specific strains and various experimental conditions.

\section{Conclusions}

In the present study, we examined 3 genetic backgrounds (ICR, C57BL/6, and B6D2F-1), 6 different developmental stages (1, 2, 4, 8-cells, morulae and blastocyst), and 4 environment factors (3 culture media and in vivo control) for mRNA stability and abundance of mouse preimplantation embryos. These required so many combinations to validate each embryo. Since we used oligo-dT to reverse transcribe the mRNAs, random hexamers in addition to oliogo-dT and/or reference-free method such as mRNA sequence for evaluation of each embryo were not checked. Therefore, the RNA extraction method, reference-free methods such as mRNA-sequence, and length of the poly-A tail, which has stability as well as regulatory functions (some mRNAs have long or short poly-A tail as part of their posttranscriptional mode of regulation) remain open. In summary, we have evaluated the expression stability of various reference genes using different culture conditions and strain backgrounds to identify suitable reference genes for normalization, and NormFinder was used to calculate the normalization factor for different rankings. The results of this study indicate that $h 2 a f z$ is a better choice than other reference genes when using a single reference gene to assess target gene expression. This study provides the first assessment of new reference genes for gene expression analysis in preimplantation mouse embryos based on culture conditions, mouse strain backgrounds, and embryonic stages. These candidates may serve as better reference genes than the traditional housekeeping genes in achieving valid and reliable analysis of gene expression.

\section{Additional files}

Additional file 1: Table S1. Composition of each medium used in this experiment.

Additional file 2: Table S2. Effects of EDTA on the development of 1 cell ICR mouse embryos in vitro.

Additional file 3: Figure S1. Selected reference gene specificity and amplification length. $\mathbf{A}$. specific PCR product was analyzed on agarose gel (1.5\%) electrophoresis for candidate housekeeping genes. Lane $\mathrm{M}$ : 100 bp DNA ladder marker. Lane 2 : ywhaz, Lane 3 : sdha, Lane 4 : tgfb1, Lane 5 : gapdh, Lane $6:$ h2afz, Lane 7 : wrnip, Lane $8:$ actb, Lane 9 : sptbn, Lane 10 : ablim, Lane 11 : 18s. B. Melting curve analysis of ten reference genes showing a single peak.

Additional file 4: Table S3. Cycle threshold values for RT- qPCR of 10 reference genes.

Additional file 5: Figure S2. Selected reference gene expression levels of transcripts in the B6D2F-1 mouse-derived pre-implantation stage embryos. The transcript levels are shown for $\mathrm{KSOM}-(\mathbf{A}), \mathrm{CZB}-\mathbf{B})$, 
M16- (C), and in vivo (D)-derived embryos. The expression at zygote stage was measured as a reference to calculate the relative amounts in the different stages.

Additional file 6: Figure S3. Candidate housekeeping gene expression levels of different transcripts detected in the C57BL/6 mouse-derived pre-implantation stage embryos. The expression levels of reference gene transcripts is shown for KSOM- (A), CZB- (B), M16- (C), and in vivo (D)-derived embryos. The expression at zygote stage was measured as a reference to calculate the relative amounts in the different stages.

Additional file 7: Figure S4. Rankings of selected housekeeping genes in in vivo-derived each stages embryos in $\mathrm{B} 6 \mathrm{D} 2 \mathrm{~F}-1$ mouse strains: A) 2-cell, B) 4-cell C) 8-cell D) morulae, and E) blastocyst stages. Data were obtained from A-E. Standard deviation (SD) of traditional housekeeping genes using NormFinder. The most stable genes are on the left and the least stable genes on the right. The experiments were performed in triplicate; data shown represent the mean of three independent experiments.

Additional file 8: Figure S5. Average stability rankings of ten endogenous reference genes in each stages embryos in C57BL/6 mouse strains: 2-cell, B) 4- cell, C) 8-cell, D) morulae, and E) blastocyst stages. Data were obtained from $\mathbf{A}-\mathbf{E}$ and analyzed for the SD of endogenous reference genes using the NormFinder program. The most stable genes are on the left and the least stable genes on the right. The experiments were performed in triplicate; data shown represent the mean of three independent experiments.

Additional file 9: Figure S6. Rankings of ten housekeeping genes in in vivo-derived each stages embryos in ICR mouse strains: 2-cell, B) 4- cell, C) 8-cell, D) morulae, and E) blastocyst stages. Data were obtained from A-E, respectively. Ranking is based on the principle that gene pairs have stable expression patterns relative to each other and are considered appropriate housekeeping genes. The most stable genes are on the left and the least stable genes on the right. The experiments were performed in triplicate; data shown represent the mean of three independent experiments.

\section{Competing interests}

The authors declare that they have no competing interests.

\section{Authors' contributions}

$J-K J$ and M-HK performed experimental design, embryos culture, and RT-PCR. SG, S-GC, CP, and HGS performed analyzed RT-PCR data. J-HK supervised the project and wrote the manuscript. All authors discussed the results, commented and approved the final manuscript.

\section{Acknowledgement}

This paper was written as part of Konkuk University's research support program for its faculty on sabbatical leave in 2013.

\section{Funding}

This paper was performed by next generation of Biogreen 21 (PJ009107) from the Rural Development Administration (RDA), Republic of Korea.

Received: 9 March 2014 Accepted: 5 September 2014 Published: 25 September 2014

\section{References}

1. Whittingham DG: Culture of mouse ova. J Reprod Fertil Supp/ 1971, 14:7-21.

2. Chatot $\mathrm{CL}$, Ziomek CA, Bavister BD, Lewis JL, Torres I: An improved culture medium supports development of random-bred 1-cell mouse embryos in vitro. J Reprod Fertil 1989, 86:679-688.

3. Lawitts JA, Biggers JD: Culture of preimplantation embryos. Methods Enzymol 1993, 225:153-164.

4. Baltz JM: Media composition: salts and osmolality. Methods Mol Biol 2012, 912:61-80.

5. Dawson KM, Collins JL, Baltz JM: Osmolarity-dependent glycine accumulation indicates a role for glycine as an organic osmolyte in early preimplantation mouse embryos. Biol Reprod 1998, 59:225-232.

6. Hadi T, Hammer MA, Algire C, Richards T, Baltz JM: Similar effects of osmolarity, glucose, and phosphate on cleavage past the 2-cell stage in mouse embryos from outbred and F1 hybrid females. Biol Reprod 2005, 72:179-187.

7. Gardner DK, Lane M: Amino acids and ammonium regulate mouse embryo development in culture. Biol Reprod 1993, 48:377-385.

8. Lane M, Gardner DK: Inhibiting 3-phosphoglycerate kinase by EDTA stimulates the development of the cleavage stage mouse embryo. Mol Reprod Dev 2001, 60:233-240.

9. Biggers JD, Whittingham DG, Donahue RP: The pattern of energy metabolism in the mouse oocyte and zygote. Proc Natl Acad Sci U S A 1967, 58:560-567.

10. Kaufman MH, Sachs L: Complete preimplantation development in culture of parthenogenetic mouse embryos. J Embryol Exp Morphol 1976, 35:179-190.

11. Quinn P, Harlow GM: The effect of oxygen on the development of preimplantation mouse embryos in vitro. J Exp Zool 1978, 206:73-80

12. Whitten WK, Biggers JD: Complete development in vitro of the preimplantation stages of the mouse in a simple chemically defined medium. J Reprod Fertil 1968, 17:399-401.

13. Brambrink T, Wabnitz P, Halter R, Klocke R, Carnwath J, Kues W, Wrenzycki C, Paul D, Niemann H: Application of CDNA arrays to monitor mRNA profiles in single preimplantation mouse embryos. Biotechniques 2002, 33:376-378. 380, 382-5.

14. Bustin $\mathrm{S}$ : Absolute quantification of mRNA using real-time reverse transcription polymerase chain reaction assays. J Mol Endocrinol 2000, 25:169-193.

15. Kurimoto K, Yabuta $Y$, Ohinata $Y$, Ono Y, Uno KD, Yamada RG, Ueda HR, Saitou M: An improved single-cell cDNA amplification method for efficient high-density oligonucleotide microarray analysis. Nucleic Acids Res 2006, 34:e42.

16. Abe K, Ko MS, Macgregor GR: A systematic molecular genetic approach to study mammalian germline development. Int J Dev Biol 1998, 42:1051-1065

17. Collins J, Fleming T: Specific mRNA detection in single lineage-marked blastomeres from preimplantation embryos. Trends Genet 1995, 11:5-7.

18. Park MR, Hwang KC, Bui HT, Cho SG, Park C, Song H, Oh JW, Kim JH: Altered gene expression profiles in mouse tetraploid blastocysts. J Reprod Dev 2012, 58:344-352.

19. Tanaka TS, Jaradat SA, Lim MK, Kargul GJ, Wang X, Grahovac MJ, Pantano S, Sano Y, Piao Y, Nagaraja R, Doi H, Wood WH, Wood WH III, Becker KG, Ko MS: Genome-wide expression profiling of mid-gestation placenta and embryo using a 15,000 mouse developmental CDNA microarray. Proc Natl Acad Sci U S A 2000, 97:9127-9132.

20. Campbell WJ, Miller KA, Anderson TM, Shull JD, Rizzino A: Expression of fibroblast growth factor receptors by embryonal carcinoma cells and early mouse embryos. In Vitro Cell Dev Biol 1992, 28A:61-66.

21. Zou JW, Sun MX, Yang HY: Single-embryo RT-PCR assay to study gene expression dynamics during embryogenesis inArabidopsis thaliana. Plant Mol Biol Report 2002, 20:19-26.

22. Goossens K, Van Soom A, Van Poucke M, Vandaele L, Vandesompele J, Van Zeveren A, Peelman LJ: Identification and expression analysis of genes associated with bovine blastocyst formation. BMC Dev Biol 2007, 7:64.

23. Vandesompele J, De Preter K, Pattyn F, Poppe B, Van Roy N, De Paepe A Speleman F: Accurate normalization of real-time quantitative QPCR data by geometric averaging of multiple internal controls. Genome Biol 2002, 3:34.

24. Jeong YJ, Choi HW, Shin HS, Cui XS, Kim NH, Gerton GL, Jun JH: Optimization of real time RT-PCR methods for the analysis of gene expression in mouse eggs and preimplantation embryos. Mol Reprod Dev 2005, 71:284-289.

25. Mamo $S$, Gal AB, Bodo $S$, Dinnyes A: Quantitative evaluation and selection of reference genes in mouse oocytes and embryos cultured in vivo and in vitro. BMC Dev Biol 2007, 7:14.

26. Veazey KJ, Golding MC: Selection of stable reference genes for quantitative rt-PCR comparisons of mouse embryonic and extraembryonic stem cells. PLoS One 2011, 6:e27592.

27. Llobat L, Marco-Jimenez F, Penaranda DS, Saenz-De-Juano MD, Vicente JS: effect of embryonic genotype on reference gene selection for RT-qPCR normalization. Reprod Domest Anim 2012, 47:629-634.

28. Filliers M, Goossens $K$, Van Soom A, Merlo B, Pope CE, De Rooster H, Smits $K$, Vandaele L, Peelman L: Gene expression profiling of pluripotency and differentiation-related markers in cat oocytes and preimplantation embryos. Reprod Fertil Dev 2012, 24:691-703. 
29. Kuijk EW, Du Puy L, Van Tol HT, Haagsman HP, Colenbrander B, Roelen BA: Validation of reference genes for quantitative RT-PCR studies in porcine oocytes and preimplantation embryos. BMC Dev Biol 2007, 7:58.

30. Bower NI, Moser RJ, Hill JR, Lehnert SA: Universal reference method for real-time PCR gene expression analysis of preimplantation embryos. Biotechniques 2007, 42:199-206.

31. Mamo S, Carter F, Lonergan P, Leal CL, Al Naib A, Mcgettigan P, Mehta JP, Evans AC, Fair T: Sequential analysis of global gene expression profiles in immature and in vitro matured bovine oocytes: potential molecular markers of oocyte maturation. BMC Genomics 2011, 12:151.

32. Vallee M, Dufort I, Desrosiers S, Labbe A, Gravel C, Gilbert I, Robert C, Sirard MA: Revealing the bovine embryo transcript profiles during early in vivo embryonic development. Reproduction 2009, 138:95-105.

33. Paris DB, Kuijk EW, Roelen BA, Stout TA: Establishing reference genes for use in real-time quantitative PCR analysis of early equine embryos. Reprod Fertil Dev 2011, 23:353-363.

34. Braude $P$, Bolton V, Moore S: Human gene expression first occurs between the four- and eight-cell stages of preimplantation development. Nature 1988, 332:459-461.

35. Huang X, Hao C, Shen X, Liu X, Shan Y, Zhang Y, Chen L: Differences in the transcriptional profiles of human cumulus cells isolated from $\mathrm{MI}$ and MII oocytes of patients with polycystic ovary syndrome. Reproduction 2013, 145:597-608.

36. Hamatani T, Carter MG, Sharov AA, Ko MSH: Dynamics of global gene expression changes during mouse preimplantation development. Dev Cell 2004, 6:117-131.

37. Santos F, Hendrich B, Reik W, Dean W: Dynamic reprogramming of DNA methylation in the early mouse embryo. Dev Biol 2002, 241:172-182.

38. Bui H-T, Wakayama S, Mizutani E, Park K-K, Kim J-H, Van Thuan N, Wakayama $T$ : Essential role of paternal chromatin in the regulation of transcriptional activity during mouse preimplantation development. Reproduction 2011, 141:67-77.

39. Gardner DK, Lane M, Calderon I, Leeton J: Environment of the preimplantation human embryo in vivo: metabolite analysis of oviduct and uterine fluids and metabolism of cumulus cells. Fertil Steril 1996, 65:349-353.

40. Lazzari G, Colleoni S, Duchi R, Galli A, Houghton FD, Galli C: Embryonic genotype and inbreeding affect preimplantation development in cattle. Reproduction 2011, 141:625-632.

41. Marikawa Y, Alarcón VB: Establishment of trophectoderm and inner cell mass lineages in the mouse embryo. Mol Reprod Dev 2009, 76:1019-1032.

42. Zhong HY, Chen JW, Li CQ, Chen L, Wu JY, Chen JY, Lu WJ, Li JG: Selection of reliable reference genes for expression studies by reverse transcription quantitative real-time PCR in litchi under different experimental conditions. Plant Cell Rep 2011, 30:641-653.

43. Dheda K, Huggett J, Bustin S, Johnson M, Rook G, Zumla A: Validation of housekeeping genes for normalizing RNA expression in real-time PCR. Biotechniques 2004, 37:112-114.

44. Eisen J: Zebrafish make a big splash. Cell 1996, 87:969-977.

45. Tang R, Dodd A, Lai D, Mcnabb W, Love D: Validation of Zebrafish (Danio rerio) reference genes for quantitative real-time qpcr normalization. Acta Biochim Biophys Sin 2007, 39:384-390.

46. Huggett J, Dheda K, Bustin S, Zumla A: Real-time QPCR normalisation; strategies and considerations. Genes Immun 2005, 6:279-284.

47. Fernandez P, DI Rienzo JA, Moschen S, Dosio GA, Aguirrezabal LA, Hopp HE, Paniego N, Heinz RA: Comparison of predictive methods and biological validation for $\mathrm{qPCR}$ reference genes in sunflower leaf senescence transcript analysis. Plant Cell Rep 2011, 30:63-74.

48. Selim M, Legay S, Berkelmann-Lohnertz B, Langen G, Kogel KH, Evers D: Identification of suitable reference genes for real-time RT-PCR normalization in the grapevine-downy mildew pathosystem. Plant Cell Rep 2012, 31:205-216.

49. Bustin S: Quantification of mRNA using real-time reverse transcription (PCR QPCR): trends and problems. J Mol Endocrinol 2002, 29:23-39.

50. Leidenfrost $S$, Boelhauve $M$, Reichenbach M, Güngör T, Reichenbach H-D, Sinowatz F, Wolf E, Habermann FA: Cell arrest and cell death in mammalian preimplantation development: lessons from the bovine model. PLoS One 2011, 6:e22121.

51. Lequarre AS, Grisart B, Moreau B, Schuurbiers N, Massip A, Dessy F: Glucose metabolism during bovine preimplantation development: analysis of gene expression in single oocytes and embryos. Mol Reprod Dev 1997, 48:216-226.
52. Park M-R, Gurunathan S, Choi Y-J, Kwon D-N, Han J-W, Cho S-G, Park C, Seo HG, Kim J-H: Chitosan nanoparticles cause pre- and postimplantation embryo complications in mice. Biol Reprod 2013, 88(88):1-13.

53. Erkman L, Yates PA, Mclaughlin T, Mcevilly RJ, Whisenhunt T, O'connell SM, Krones Al, Kirby MA, Rapaport DH, Bermingham JR, O'Leary DD, Rosenfeld MG: A POU domain transcription factor-dependent program regulates axon pathfinding in the vertebrate visual system. Neuron 2000, 28:779-792.

54. Lloyd C, Gunning P: beta- and gamma-actin genes differ in their mechanisms of down-regulation during myogenesis. J Cell Biochem 2002, 84:335-342.

55. Oishi M, Gohma H, Hashizume K, Taniguchi Y, Yasue H, Takahashi S, Yamada $T$, Sasaki Y: Early embryonic death-associated changes in genome-wide gene expression profiles in the fetal placenta of the cow carrying somatic nuclear-derived cloned embryo. Mol Reprod Dev 2006, 73:404-409.

56. Garcia-Herreros M, Aparicio IM, Rath D, Fair T, Lonergan P: Differential glycolytic and glycogenogenic transduction pathways in male and female bovine embryos produced in vitro. Reprod Fertil Dev 2012, 24:344-352.

57. Mack HI, Zheng B, Asara JM, Thomas SM: AMPK-dependent phosphorylation of ULK1 regulates ATG9 localization. Autophagy 2012, 8:1197-1214.

58. Finley LW, Haas W, Desquiret-Dumas V, Wallace DC, Procaccio V, Gygi SP, Haigis MC: Succinate dehydrogenase is a direct target of sirtuin 3 deacetylase activity. PLoS One 2011, 6:e23295

59. Iwamoto D, Kasamatsu A, Ideta A, Urakawa M, Matsumoto K, Hosoi Y, Iritani A, Aoyagi Y, Saeki K: Donor cells at the G1 phase enhance homogeneous gene expression among blastomeres in bovine somatic cell nuclear transfer embryos. Cell Reprogram 2012, 14:20-28.

60. Kuchipudi SV, Tellabati M, Nelli RK, White GA, Perez BB, Sebastian S, Slomka MJ, Brookes SM, Brown IH, Dunham SP, Chang KC: 18S rRNA is a reliable normalisation gene for real time PCR based on influenza virus infected cells. Virol J 2012, 9:230.

61. Fried $G$, Wramsby $H$ : Increase in transforming growth factor beta1 in ovarian follicular fluid following ovarian stimulation and in-vitro fertilization correlates to pregnancy. Hum Reprod 1998, 13:656-659.

62. Samuel MS, Lundgren-May T, Ernst M: Identification of putative targets of DNA (cytosine-5) methylation-mediated transcriptional silencing using a novel conditionally active form of DNA methyltransferase $3 a$. Growth Factors 2007, 25:426-436.

63. Castro CB, Whittock LD, Whittock SP, Leggett $G$, Koutoulis A: DNA sequence and expression variation of hop (Humulus lupulus) valerophenone synthase (VPS), a key gene in bitter acid biosynthesis. Ann Bot 2008, 102:265-273.

64. Matousek J, Kocabek T, Patzak J, Skopek J, Maloukh L, Heyerick A, Fussy Z, Roldan-Ruiz I, Keukeleire DD: HIMyb3, a putative regulatory factor in hop (Humulus lupulus L.), shows diverse biological effects in heterologous transgenotes. J Agric Food Chem 2007, 55:7767-7776.

65. Nagel J, Culley LK, Lu Y, Liu E, Matthews PD, Stevens JF, Page JE: EST analysis of hop glandular trichomes identifies an O-methyltransferase that catalyzes the biosynthesis of xanthohumol. Plant Cell 2008, 20:186-200

66. Chang Z, Ling C, Yamashita M, Welham NV: Microarray-driven validation of reference genes for quantitative real-time polymerase chain reaction in a rat vocal fold model of mucosal injury. Anal Biochem 2010, 406:214-221.

67. Nicot N, Hausman JF, Hoffmann L, Evers D: Housekeeping gene selection for real-time RT-PCR normalization in potato during biotic and abiotic stress. J Exp Bot 2005, 56:2907-2914.

68. Radonic A, Thulke S, Mackay IM, Landt O, Siegert W, Nitsche A: Guideline to reference gene selection for quantitative real-time PCR. Biochem Biophys Res Commun 2004, 313:856-862.

69. Sturzenbaum SR, Kille P: Control genes in quantitative molecular biological techniques: the variability of invariance. Comp Biochem Physiol B Biochem Mol Biol 2001, 130:281-289.

doi:10.1186/1756-0500-7-675

Cite this article as: Jeong et al:: Evaluation of reference genes in mouse preimplantation embryos for gene expression studies using real-time quantitative RT-PCR (RT-qPCR). BMC Research Notes 2014 7:675. 